\title{
Uma nova espécie de Youngomyia (Diptera, Cecidomyiidae) do Brasil
}

\author{
Alene R. Rodrigues \& Valéria C. Maia \\ Museu Nacional, Quinta da Boa Vista, São Cristóvão, 20940-040 Rio de Janeiro, RJ, Brasil. (alenerodrigues@yahoo.com.br)
}

\begin{abstract}
A new species of Youngomyia (Diptera, Cecidomyiidae) of Brazil. A new species of Youngomyia Felt, 1908, inquiline in galls on inflorescences of Jacquemontia holosericea (Convolvulaceae), is described (larva, pupa, male and female) based on material from Rio de Janeiro, Brazil.
\end{abstract}

KEYWORDS. Gall midges, Jacquemontia, taxonomy.

RESUMO. Uma nova espécie de Youngomyia Felt, 1908, inquilina de galhas em botão floral de Jacquemontia holosericea (Convolvulaceae), é descrita (larva, pupa, macho e fêmea) baseado em material do Rio de Janeiro, Brasil.

PALAVRAS-CHAVE. Inseto galhador, Jacquemontia, taxonomia.

Youngomyia Felt, 1908 inclui seis espécies, três neotropicais: Y. cinctipes (Felt, 1915), Y. knabi (Felt, 1912) e Y. pouteriae Maia, 2001, uma oriental: Y. spinosa Grover, 1979, uma neártica: Y. quercina Felt, 1911 e uma com ocorrência nas Regiões Neotropical e Neártica: $Y$. podophyllae (Felt, 1907) (GAGNÉ, 2004). Quatro das espécies conhecidas desse gênero são inquilinas de galhas. Das outras duas não se conhece o hábito, uma vez que são descritas apenas dos adultos capturados em voo.

Esse gênero caracteriza-se pelo seguinte conjunto de caracteres: $R_{S}$ incompleta com posição variável, situada levemente antes ou depois da metade de $\mathrm{R}_{1}$; flagelômeros masculinos alongados e tricircunfilares; fêmeas com numerosos conectivos circunfilares; hastes dos flagelômeros pilosas; garras tarsais fortemente curvadas após $1 / 3$ basal; gonocoxitos com lobo mesobasal setuloso; gonóstilo longo; hipoprocto com pequenos espinhos muito aproximados entre si na metade posterior e edeago de forma variável (GAGNÉ, 1994).

Neste artigo, uma nova espécie inquilina de galhas induzidas por Schizomyia santosi Maia \& Araújo, 2009 (Diptera, Cecidomyiidae) em Jacquemontia holosericea (Convolvulaceae) é descrita e ilustrada.

Jacquemontia holosericea tem ocorrência registrada apenas no Brasil, nos estados do Ceará, Rio de Janeiro, São Paulo e Santa Catarina. Esta planta é facilmente encontrada na restinga da Barra de Maricá e de Itaipuaçu, RJ, ocorrendo ao longo da estrada paralela à Praia de Zacarias e de Itaipuaçu, respectivamente (MAIA, 2001).

\section{MATERIAL E MÉTODOS}

O material examinado faz parte da coleção de Diptera do Museu Nacional do Rio de Janeiro (MNRJ) e foi obtido por meio de coletas de galhas nos botões florais de Jacquemontia holosericea realizadas na restinga da Barra de Maricá e de Itaipuaçu, Rio de Janeiro.

Os espécimes encontram-se montados em lâminas permanentes de microscopia, em bálsamo do Canadá. O gênero foi determinado utilizando-se a chave genérica de GaGné (1994) e a espécie foi considerada como nova por meio de comparação com as descrições originais das demais espécies e exame de exemplares de Youngomyia pouteriae. As ilustrações foram realizadas com auxílio de câmara clara acoplada a microscópio óptico. Medidas são apresentadas em milímetros ( $\mathrm{mm}$ ).

\section{Youngomyia floricola sp. nov. (Figs 1-15)}

Diagnose. Adulto: flagelômeros com haste não pilosa, em ambos os sexos; garras tarsais simples; terminália masculina com gonocoxitos estreitos e alongados, gonóstilos afilados, cercos arredondados, hipoprocto e edeago estreitos; ovipositor curto, cercos femininos ovóides. Pupa: chifre antenal reduzido, espiráculos protorácicos alongados e cerdiformes, espinhos dorsais abdominais presentes. Larva: espátula protorácica com três dentes apicais, dois bem desenvolvidos e o mediano reduzido.

Adulto. Comprimento do corpo: 1,65-2,2 nos machos $(n=4) ; 2,27$ nas fêmeas ( $n=2)$. Cabeça (Figs 1, 7): olhos com facetas circulares, mais unidas na parte superior que na metade inferior. Antena com escapo bem desenvolvido, pedicelo globoso; machos com flagelômeros binodais e tricircunfilares, circunfilo basal e o mediano de igual comprimento, circunfilo distal mais curto (Fig. 2); fêmeas com flagelômeros cilíndricos e circunfilos na forma de dois anéis horizontais conectados, formando um X (Fig. 8); hastes nuas e alongadas em ambos os sexos, hastes dos machos maiores que as das fêmeas; $12^{\circ}$ flagelômero com prolongamento apical em ambos os sexos, mais curto nas fêmeas; flagelômeros $1 \mathrm{e}$ 2 unidos, em ambos os sexos. Palpos com quatro segmentos.

Tórax. Comprimento da asa: 1,5-1,65 nos machos $(n=3)$ (Fig. 3); 1,3-1,65 nas fêmeas $(n=2)$. Asas com $R_{S}$ fraca e incompleta; $\mathrm{M}_{3}$ presente; $\mathrm{Cu}$ bifurcada em ambos os sexos; $\mathrm{R}_{5}$ unindo-se à $\mathrm{C}$ após o ápice da asa; primeiro tarsômero sem "esporão" (Fig. 4); garras tarsais simples, 
curvadas após $2 / 3$ basais, empódio quase tão longo quanto as garras (Fig. 5).

Abdômen. Macho (Fig. 6): tergitos 1-6 retangulares com linha completa de cerdas caudais e um par de sensilas basais. Tergito $7 \mathrm{com}$ margem caudal fracamente esclerotizada e um par de sensilas basais. Tergito 8 menos esclerotizado e com um par de sensilas basais. Esternitos 2-7 retangulares com linha completa de cerdas caudais, diversas cerdas mesais irregularmente distribuídas e um par de sensilas basais. Esternito 8 não esclerotizado. Fêmea (Fig. 9): tergitos 1-8 retangulares com uma linha completa de cerdas caudais e um par de sensilas basais. Esternitos 2-8 retangulares com uma linha completa de cerdas caudais, diversas cerdas mesais irregularmente distribuídas e um par de sensilas basais.

Terminália do macho. Gonocoxitos com curtos lobos mesobasais setulosos; gonóstilos afilados e alongados apresentando um único dente; cerco bilobado mais comprido que o hipoprocto e com cerdas apicais; hipoprocto curto, menor que a metade do edeago, com ápice com inúmeras cerdas esclerotizadas; parâmeros ausentes; edeago afilado gradualmente da base para o ápice, com o mesmo comprimento que os gonocoxitos (Fig. 10). Ovipositor: curto, cerco ovóide não fusionado, com muitas cerdas concentradas na região ventral (Fig. 11).

Pupa. Comprimento do corpo: 2,54 ( $\mathrm{n}=1)$. Chifres antenais reduzidos (Fig. 12); cerda apical alongada, com 0,13 de comprimento ( $\mathrm{n}=1$ ) (Fig. 12); dois pares de papilas faciais inferiores (um par com cerda e um nu), três pares de papilas faciais laterais (um com cerda e dois nus) (Fig. 12); espiráculo protorácico longo e cerdiforme, com 0,24 de comprimento ( $\mathrm{n}=1)$ (Fig. 12). Segmentos abdominais 2-8 com uma fileira de espinhos conspícuos na região mesal, próxima à margem anterior de cada tergito (Fig. 13).

Larva (Fig. 14). Comprimento do corpo: $3,1(\mathrm{n}=1)$. Corpo alongado e cilíndrico, afilando gradualmente em direção à extremidade caudal. Tegumento rugoso e granuloso. Espátula com 0,22 de comprimento, tridentada (com dois dentes bem desenvolvidos e um reduzido) e haste pouco esclerotizada (Fig. 15); papilas esternais, laterais e terminais e posição do ânus não visíveis no material.
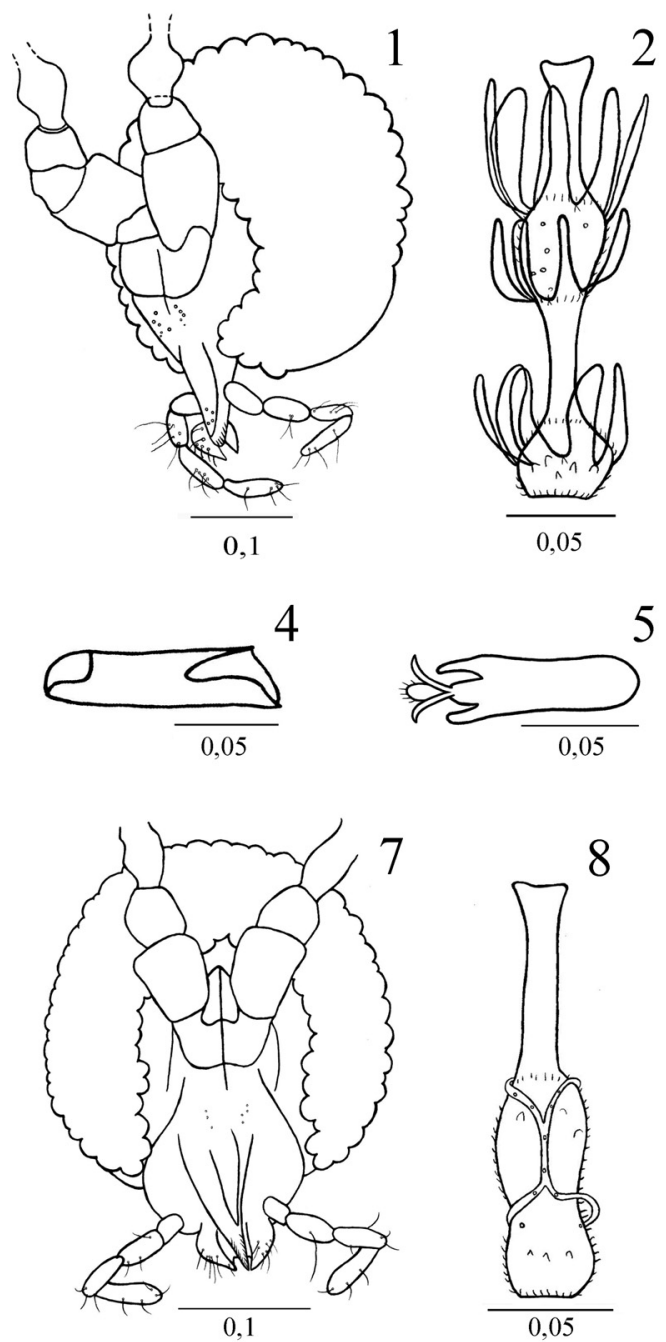
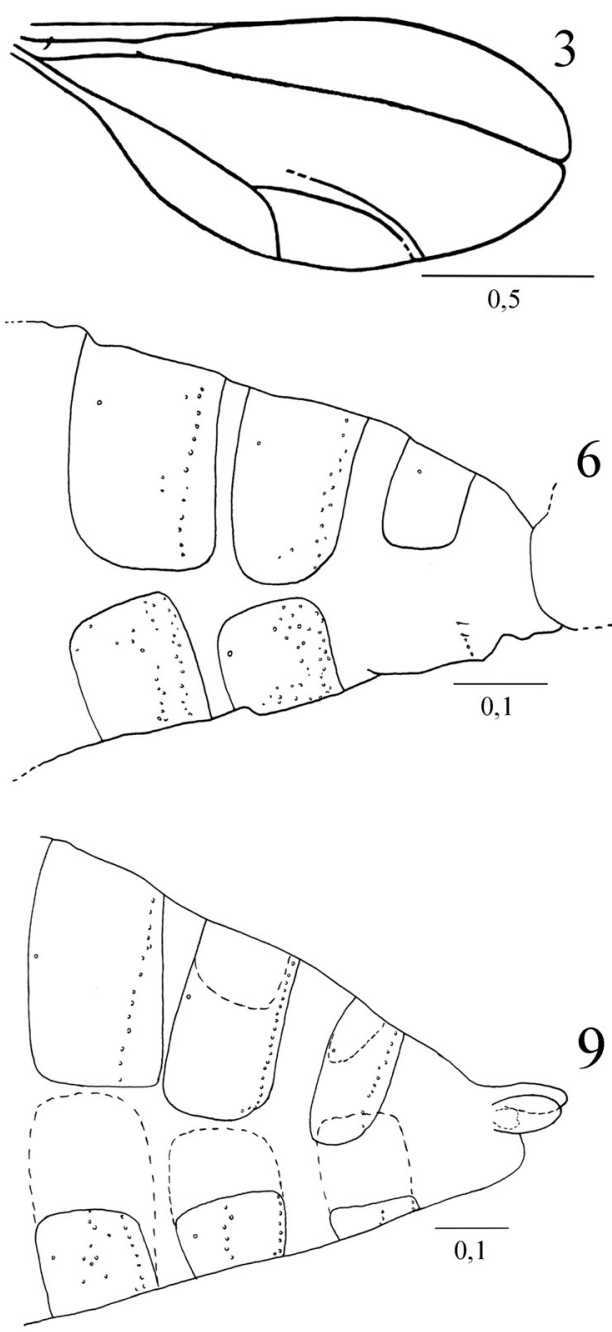

Figuras 1-9. Youngomyia floricola sp. nov. Macho: 1, cabeça, vista frontolateral; 2, flagelômero antenal 5; 3, asa; 4, perna anterior, primeiro tarsômero; 5, perna anterior, garra e empódio; 6, segmentos abdominais 6-8, vista lateral. Fêmea: 7, cabeça, vista frontal; 8, flagelômero antenal 3; 9, segmentos abdominais 6-8, vista lateral. Barras em mm. 

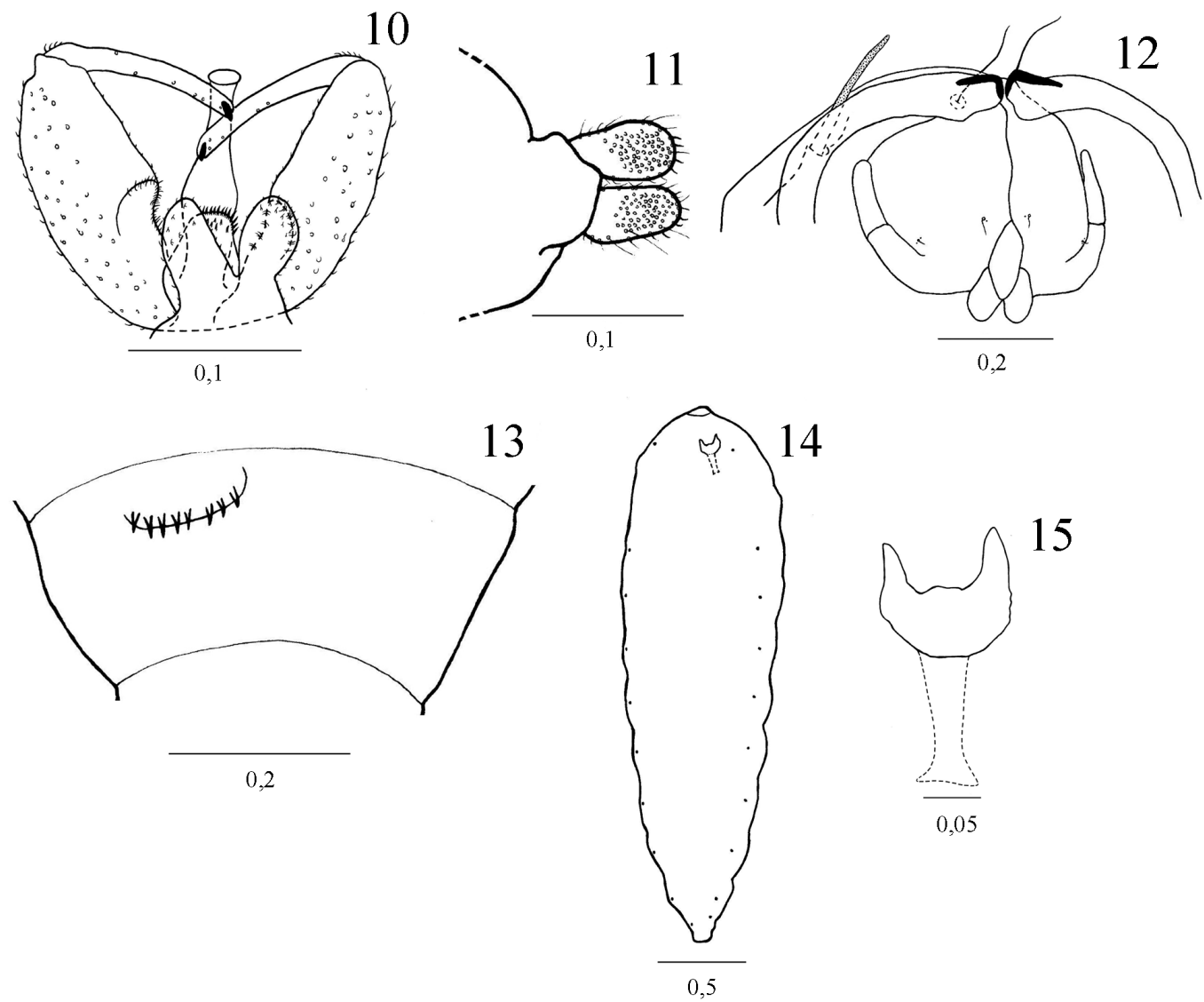

Figuras 10-15. Youngomyia floricola sp. nov. 10, terminália masculina, vista dorsal; 11, ovipositor, vista dorsal; 12, 13. Pupa: 12, região cefálica; 13 , segmento abdominal 7, vista dorsal; 14, 15. Larva: 14, aspecto geral; 15, espátula protorácica, vista ventral. Barras em mm.

Tipos. Holótipo $0^{\top}$. BRASIL, Rio de Janeiro: Maricá (restinga da Barra de Maricá, 42 ${ }^{\circ} 54^{\prime} 00^{\prime \prime}, 42^{\circ} 50$ '03' $\mathrm{W}$; $22^{\circ} 58^{\prime} 05^{\prime \prime}, 22^{\circ} 57^{\prime} 37^{\prime}$ 'S), 20.XI.2000, V. C. Maia \& M. A. P. Azevedo col. Parátipos: $3 \sigma^{7}$ mesma procedência e data do holótipo; $20^{\prime}, 3$ 우 (restinga de Itaipuaçu, 42 $54^{\prime} 13^{\prime \prime}, 43^{\circ} 00^{\prime} 47^{\prime \prime} \mathrm{W}$; 2258'14", 22 58'13"S) (em uma das lâminas, além da fêmea, há uma larva de Cecidomyiidae não determinado), 1 exúvia, 2 larvas, 01.VIII.1998, V. C. Maia col.

Etimologia. O epíteto específico refere-se ao órgão de ocorrência da galha na planta.

\section{DISCUSSÃO}

A nova espécie difere de $Y$. knabi, $Y$. cinctipes e $Y$. pouteriae pela forma dos cercos femininos (alongados $\mathrm{e}$ estreitos nessas e ovóide na espécie nova). Além disso, são facilmente distinguíveis dos machos de $Y$. knabi e de $Y$. pouteriae pela forma dos gonocoxitos (quadrados na primeira, ovóides e amplos na segunda e mais estreitos e alongados na espécie nova) e dos cercos (triangulares na primeira, delgados na segunda e arredondados na espécie nova). Difere de $Y$. pouteriae também pela forma dos gonóstilos (mais delgado na espécie nova), do hipoprocto e do edeago (nitidamente mais estreitos na espécie nova). Dentre todas as espécies neotropicais conhecidas, assemelha-se mais a Y. podophylla pela forma dos cercos femininos.

Agradecimentos. À Dra. Maria Antonieta Pereira de Azevedo pelo auxílio na coleta das galhas e ao CNPq pelo apoio financeiro (Proc. 301197/2007-5).

\section{REFERÊNCIAS BIBLIOGRÁFICAS}

GagnÉ, R. J. 1994. The gall midges of the Neotropical region. Ithaca, Cornell University. 352p.

2004. A Catalog of the Cecidomyiidae (Diptera) of the world. Memoirs of the Entomological Society of Washington 25:1-408.

MaIA, V. C. 2001. The gall midges (Diptera, Cecidomyiidae) from three restingas of Rio de Janeiro State, Brazil. Revista Brasileira de Zoologia 18(2):305-656. 